\section{CORRECTION}

View Article Online

View Journal I View Issue

\section{A) Check for updates}

Cite this: Food Funct., 2021, 12, 8813

\title{
Correction: Inhibition of NLRP3 inflammasome activation and pyroptosis with the ethyl acetate fraction of Bungeanum ameliorated cognitive dysfunction in aged mice
}

\author{
Meihuan Zhao, ${ }^{a, b}$ Yuan Dai, ${ }^{b, c}$ Ping Li, ${ }^{a, b}$ Jie Wang, ${ }^{a, b}$ Tengyun Ma ${ }^{a, b}$ and \\ Shijun $X u^{* a, b}$
}

Correction for 'Inhibition of NLRP3 inflammasome activation and pyroptosis with the ethyl acetate frac-

DOI: $10.1039 / \mathrm{d} 1$ fo90071d tion of Bungeanum ameliorated cognitive dysfunction in aged mice' by Meihuan Zhao et al., Food Funct., 2021, DOI: 10.1039/D1FO00876E.

rsc.li/food-function

The authors regret that an incorrect project number was shown in the acknowledgements section of the published article. The corrected section should read:

The authors are grateful for the assistance from all the staff members of the Institute of Material Medica Integration and Transformation for Brain Disorders. This research was supported by the Applied Basic Research Project of Sichuan Province (no. 2021YJ0009), the Key Research and Development Plan of Sichuan Province (no. 19ZDYF0600), and the Xinglin Scholar Research Premotion Project of Chengdu University of TCM (no. CXTD2018013).

The Royal Society of Chemistry apologises for these errors and any consequent inconvenience to authors and readers.

\footnotetext{
${ }^{a}$ School of Pharmacy, Chengdu University of Traditional Chinese Medicine, Chengdu, 611137, PR China. E-mail: xushijun@cdutcm.edu.cn; Fax: +86-288-2799671; Tel: +86-028-61800231

${ }^{b}$ Institute of Material Medica Integration and Transformation for Brain Disorders, Chengdu University of Traditional Chinese Medicine, Chengdu, 611137, PR China ${ }^{c}$ School of Health Preservation and Rehabilitation, Chengdu University of Traditional Chinese Medicine, Chengdu, Sichuan 611137, PR China
} 